\title{
Alopecia-epilepsy-pyorrhea-intellectual disability syndrome
}

INSERM

\section{Source}

INSERM. (1999). Orphanet: an online rare disease and orphan drug data base. Alopeciaepilepsy-pyorrhea-intellectual disability syndrome. ORPHA:1008

Alopecia-epilepsy-pyorrhea-intellectual disability syndrome is characterized by congenital permanent alopecia universalis, intellectual disability, psychomotor epilepsy and periodontitis (pyorrhea). Total permanent alopecia and pyorrhea are invariably concomitant while intellectual disability and psychomotor epilepsy are observed in most patients. No other abnormality of nails or skin (apart from absence of hair) has been reported. Transmission is autosomal dominant. 